\title{
Targeting CXCR4 with CTCE-9908 inhibits prostate tumor metastasis
}

\author{
Donald Wong ${ }^{4}$, Pridvi Kandagatla ${ }^{1}$, Walter Korz ${ }^{4}$ and Sreenivasa R Chinni ${ }^{1,2,3^{*}}$
}

\begin{abstract}
Background: CXCL12/CXCR4 transactivation of epidermal growth factor family receptors in lipid raft membrane microdomains on cell surface is thought to mediate tumor growth and subsequent development of metastatic disease. CTCE-9908 is a known inhibitor of CXCR4. Herein, we tested the efficacy of CTCE-9908 in inhibiting prostate cancer cell growth, invasion, and metastasis.

Methods: We used a panel of in vitro assays utilizing human prostate cancer cell lines and an in vivo orthotopic prostate cancer model to assess the anti-tumoral activity of CTCE-9908.

Results: We demonstrated that (a) CTCE-9908 treatment resulted in no significant change in the growth of PC-3 and C4-2B cells; (b) $50 \mu \mathrm{g} / \mathrm{ml}$ of CTCE-9908 inhibited the invasive properties of PC-3 cells; (c) $25 \mathrm{mg} / \mathrm{kg}$ of CTCE9908 did not alter primary tumor growth but it did significantly reduce total tumor burden in the animal including the growth of prostate and soft tissue metastases to lymph node and distant organ tissues. Histological analysis showed that CTCE-9908 treatment resulted in tumor necrosis in primary prostate tumors and no significant change in proliferation of tumor cells as measured by Ki-67 staining; (d) CTCE-9908 inhibited the tumor angiogenesis as measured by CD34 positive vessels in tumors.

Conclusions: These data suggest that CXCR4 inhibition by CTCE-9908 decreases the invasion potential in vitro, which then translated to a reduction of tumor spread with associated reduction in angiogenesis. Hence, CTCE-9908 may prove to be an efficacious novel agent to prevent and treat the spread of metastatic prostate cancer.
\end{abstract}

Keywords: CTCE-9908, CXCR4, CXCL12, Chemoinvasion and prostate cancer progression

\section{Background}

CXCR4 activation contributes to site-specific metastasis in several types of tumors, where circulating epithelial tumor cells express CXCR4 and common metastasis sites express abundant ligand, and ligand/receptor interaction has been shown to promote metastasis (reviewed in [1]). In prostate cancer patients, CXCR4 expression is upregulated during cancer progression [2] and aggressive cancer development $[3,4]$. We and others have previously shown that the CXCL12/CXCR4 axis plays an important role in PC cell proliferation, migration, and invasion [2,5-13]. Furthermore, we demonstrated that CXCL12/CXCR4 signals through the PI3 kinase/Akt pathway to induce matrix metalloproteinase

\footnotetext{
* Correspondence: schinni@med.wayne.edu

'Department of Urology, Wayne State University School of Medicine, 9200 Scott Hall 540 E. Canfield Avenue, Detroit, MI 48201, USA

${ }^{2}$ Department of Pathology, Wayne State University School of Medicine, 9200 Scott Hall 540 E. Canfield Avenue, Detroit, Ml 48201, USA

Full list of author information is available at the end of the article
}

(MMP) expression and secretion, ultimately leading to migration and invasion of PC cells [5]. MMPs have been shown to be involved in the metastatic growth of prostate tumors in the bone and also appear to be activated at earlier time periods of tumor growth [14]; therefore, these data provide a mechanistic connection between "homing" of cancer cells to distant sites mediated by CXCL12/CXCR4 axis and followed by expression of MMPs which mediate invasion and proliferation. Similarly, our recent data demonstrate that CXCL12 binding to CXCR4 transactivates HER2 in PC cells to initiate chemo-invasive signaling and promotion of bone tumor growth, suggesting that this pathway is not only involved in initial seeding of bone metastases but also plays a key role in subsequent osseous expansion of metastases [10]. Furthermore, neutralization of CXCR4 in prostate cancer cells with anti-CXCR4 antibodies significantly reduced metastatic burden of experimental bone metastasis [13].

\section{Biomed Central}


Targeting CXCR4 can have dual effects on inhibiting primary tumor growth and metastasis or mono effect on inhibiting either tumor growth or metastasis. Among CXCR4 inhibitors, AMD3100 is in clinical use for leukemia [15,16], and CTCE-9908 was granted approval by the FDA for osteosarcoma [17] based on its potent inhibitory activity in preclinical models of osteosarcoma [18]. AMD3100 is a bicyclam CXCR4 inhibitor that has been shown to be effective in reducing tumor growth in glioblastoma [19] and peritoneal metastasis in ovarian carcinoma [20]. CTCE9908 is a peptide antagonist for CXCR4 and has shown to inhibit both primary tumor growth and metastases in osteosarcoma [18] and breast cancer models [21]. In a prostate cancer model, CTCE-9908 caused a reduction in tumor growth in a subcutaneous xenograft model via inhibiting angiogenesis by reducing the recruitment of proangiogenic myeloid precursor cells [22]. The current study assessed the efficacy of CTCE-9908 in an orthotopic prostate cancer model of primary tumor growth and metastases. The results show that CTCE-9908 is effective in reducing total tumor burden without significantly affecting the primary tumor growth.

\section{Methods}

\section{Cell culture}

PC-3 cells were obtained from American Type Culture Collection (Manassas, VA) and cultured in RPMI 1640 (Invitrogen Life Technologies, Carlsbad, CA) supplemented with 10\% FBS and 1\% Penicillin and Streptomycin. C4-2B cells were obtained from Dr. Leeland Chung and cultured in $\mathrm{T}$ media (Invitrogen Life Technologies, Carlsbad, CA) supplemented with 10\% FBS and 1\% Penicillin and Streptomycin.

\section{Cell proliferation assay}

$1 \times 10^{4}$ PC-3 and C4-2B cells were seeded in a 96 well plate; the following day, cells were treated with varying concentrations $(0-100 \mu \mathrm{g} / \mathrm{ml})$ of CTCE-9908 dissolved in sterile $\mathrm{dH}_{2} \mathrm{O}$. After 24, 48, and 72 hours, cells were washed with PBS and exposed to $1 \mathrm{X}$ dye binding solution from $\mathrm{CyQUANT}^{\oplus} \mathrm{NF}$ cell proliferation assay kit (Molecular Probes, Eugene, OR) for $60 \mathrm{~min}$. Dye DNAbound complexes were measured at $485 \mathrm{~nm}$ excitation and $530 \mathrm{~nm}$ emission.

\section{Chemoinvasion assay}

PC-3 cells were serum-starved for 4 hours. A total of 1.5$2.0 \times 10^{5}$ cells were seeded onto inserts in the upper chamber of trans-well culture plates (Becton Dickenson, San Diego, CA). Prior to seeding, the inserts were pre-coated with Matrigel. Untreated control and CTCE-9908 (1 and $50 \mu \mathrm{g} / \mathrm{ml}$ ) pretreated PC-3 cells were seeded in Matrigel coated inserts. CXCL12 was placed in the bottom chamber to induce CXCR4-mediated chemoinvasion. After 24 hours, the upper chambers were cleaned with cotton swabs to remove non-migrated/invaded cells, and the inserts were stained with Diff-Quik stain set (Dade Behring Inc., Newark, DE). The total number of migrated cells in a high power field was counted under a microscope, and the data presented is based on three independent experiments.

\section{Orthotopic tumor growth and CTCE-9908 treatment}

PC-3-GFP cells were grown subcutaneously as a tumor stock. The animal experiments were performed at Anti Cancer Inc., (San Diego, CA) in accordance with the principles and procedures outlined in the NIH Guide for the Care and Use of Laboratory Animals under assurance number A3873-1. Subcutaneous PC3-GFP tumor was excised, the necrotic areas removed, and $1 \mathrm{~mm}^{3}$ of tumor piece was implanted in the mouse ventral lobe of the prostate [23]. Animals were treated with $25 \mathrm{mg} / \mathrm{kg} /$ day CTCE-9908 daily, through subcutaneous injection at 3 days post-orthotopic tumor implantation for four weeks. Control animals were treated with water. The whole experiment was performed in three batches with six, four and ten animals in control group to a total of 20 mice and seven, four and ten animals in CTCE-9908 group to a total of 21 mice. Four weeks post tumor implantation, caliper measurements were made to determine the orthotpic prostate tumor volume by measuring perpendicular minor dimension (W) and major dimension (L) and volume was calculated by the $\mathrm{W}^{2} \times \mathrm{L} \times 1 / 2$ formula. Whole body fluorescence measurements were made using Leica stereo fluorescence microscope (model LZ12) equipped with ST-133 Micromax high speed CCD camera (Princeton Instruments, Trenton, NJ) with anesthetized intact animals to determine total tumor burden including metastases. Starting two weeks after implantation whole body imaging was performed once a week. At the end of the study (four weeks) animals were euthanized and an open imaging was conducted to accurately document and quantitate tumor burden (primary tumors and metastatic tumor). Signals from individual organ metastasis were quantitated from control animals and CTCE-9908 treated animals.

\section{Immunohistochemistry}

Prostate tumors and lymph node metastases were paraffin embedded, and $4 \mu \mathrm{m}$ thick sections were cut using microtome. Tissue sections were immunostained with anti-cytokeratin antibody, anti-Ki-67 antibody and antiCD34 antibody. Vectastain Elite ABC kit was used to stain secondary antibody, and DAB chromagen was used to develop color. Images were captured with Axiovision software. For determining angiogenesis clusters of CD34 positive vessels (hot spots) were counted in $400 \times$ field in tumors and lymph node metastasis. 


\section{Statistical analysis}

In vitro studies, statistical significance was determined by Student t-test and non-parametric ANOVA test, while in vivo assays were analyzed by Student t-test using GraphPad Prism software version 3.0 (GraphPad, San Diego, CA). $p \leq 0.05$ was considered to be statistically significant.

\section{Results}

CXCR4 inhibition by CTCE-9908 does not inhibit cell proliferation

In an effort to determine the effect of CTCE-9908 on proliferation, $\mathrm{PC}-3$ and $\mathrm{C4}-2 \mathrm{~B}$ cells were treated with increasing concentrations of CTCE-9908 ranging from $10 \mathrm{ng} / \mathrm{ml}$ to $100 \mu \mathrm{g} / \mathrm{ml}$ for 24 to 72 hours. CTCE-9908 treatment did not significantly affect the $\mathrm{PC}-3$ cell proliferation (Figure 1). Similar trend was observed with C42B cells up to 48 treatment of CTCE-9908, but at 72 hours a modest inhibition of growth observed at higher concentrations of CTCE-9908.

\section{CTCE-9908 inhibits CXCL12-induced cell invasion}

Our previous reports demonstrate that CXCL12/CXCR4 activation induces protease expression and chemoinvasion of PC-3 cells. Herein, the effect of CTCE-9908 on CXCL12-induced chemoinvasion was tested in PC-3 cells as the drug have no growth inhibitory effect. As expected, CXCL12 induced chemoinvasion of PC-3 cells; treatment with $50 \mu \mathrm{g} / \mathrm{ml}$ CTCE-9908 significantly reduced CXCL12-induced chemoinvasion of PC-3 cells (Figure 2). These results suggest that CTCE-9908 compound inhibits the CXCL12/CXCR4 axis and subsequent chemoinvasion of PC-3 cells.

\section{CXCL12/CXCR4 inhibition by CTCE-9908 leads to} inhibition of total tumor burden

To determine the efficacy of CTCE-9908 in inhibiting CXCL12/CXCR4-mediated tumor cell growth and dissemination, an orthotopic model of prostate cancer metastasis was utilized. GFP-transfected PC-3 tumor cells were implanted into the ventral lobes of murine prostate. GFP stable transfection did not affect CXCR4 expression (data not shown). Mice were treated with a daily dose of $25 \mathrm{mg}$ CTCE-9908/ kg mouse body weight for four weeks. Caliper measurements of tumor volume at the end of four weeks show a decrease in mean tumor volume in CTCE-9908 treated animals (Figure 3B), although this decrease was not statistically significant. Proliferation index was determined in control and CTCE-9908 treated prostate tumors by immunostaining tumor sections for Ki-67 expression. There is no significant difference present between Ki-67 positive tumor cells between these groups suggesting that proliferation rate of tumor cells was not affected by the CTCE-9908
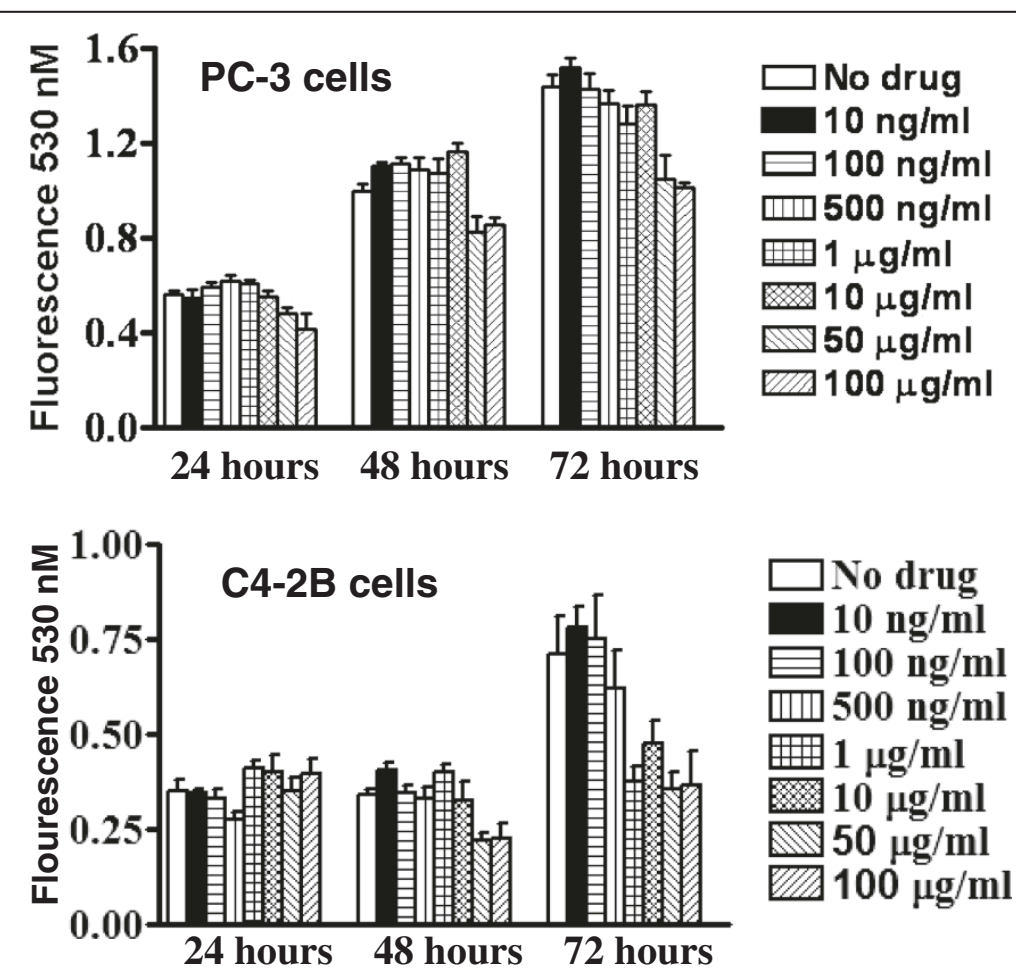

Figure 1 PC-3 cell proliferation in the presence of CTCE-9908. PC-3 and C4-2B cells were treated with 0, 10, 100, 500 ng/ml, 1, 10, 50 and $100 \mathrm{\mu g} / \mathrm{ml}$ concentrations of CTCE-9908 for 24 to 72 hours, and viable cells were determined with CyQUANT ${ }^{\oplus}$ NF cell proliferation assay. 


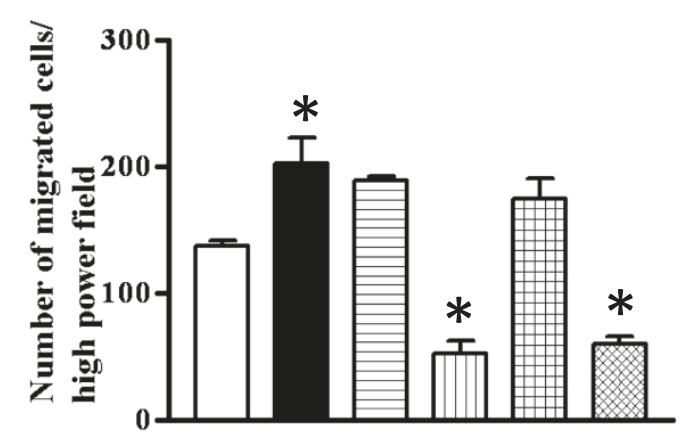

Top chamber

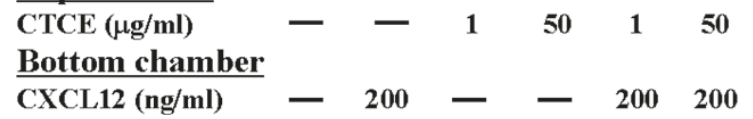

Figure 2 PC-3 cell chemoinvasion in the presence of CTCE9908. Chemonivasion of PC-3 cells were performed with Matrigelcoated inserts. PC-3 cells were pretreated with 1 and $50 \mu \mathrm{g} / \mathrm{ml}$ of CTCE-9908 for 48 hours then seeded in chemoinvasion inserts and exposed to CTCE-9908. $200 \mathrm{ng} / \mathrm{ml}$ of CXCL12 was added to the lower chamber as a chemoattractant. Invaded cells at the bottom of the filter were quantitated and shown in figure.
(Additional file 1: Figure S1). The reduction in tumor growth may be due to increased necrosis of tumor cells as evidenced by low cytokeratin staining in CTCE-9908 treated mice (Additional file 2: Figure S2) which resulted in shrinkage of tumor.

CTCE-9908 treatment significantly reduced lymph node metastasis and distant metastases in orthotopic mouse model (Figure 3A), however significant reduction in primary tumor burden was not evident (Figure 3B). Total body fluorescence measurements show that CTCE-9908 treatment significantly inhibited total metastatic burden in mice (Figure 3C). Quantitation of sitespecific metastases show that lymph node metastases were reduced by $40 \%$, spleen metastasis by $75 \%$, liver metastasis by $93 \%$, and $95 \%$ reduction in distant metastases in CTCE-9908 treated mice (data not shown). Taken together, these data demonstrate that CTCE-9908 administration significantly inhibited dissemination of cancer cells to various sites in the mouse.

CTCE-9908 inhibits angiogenesis in prostate tumor tissues Primary tumor tissue from control and CTCE-9908treated mice were stained with anti-CD34 antibody to determine the effect of CTCE-9908 on tumor angiogenesis. As shown by immunohistochemistry, CTCE-9908

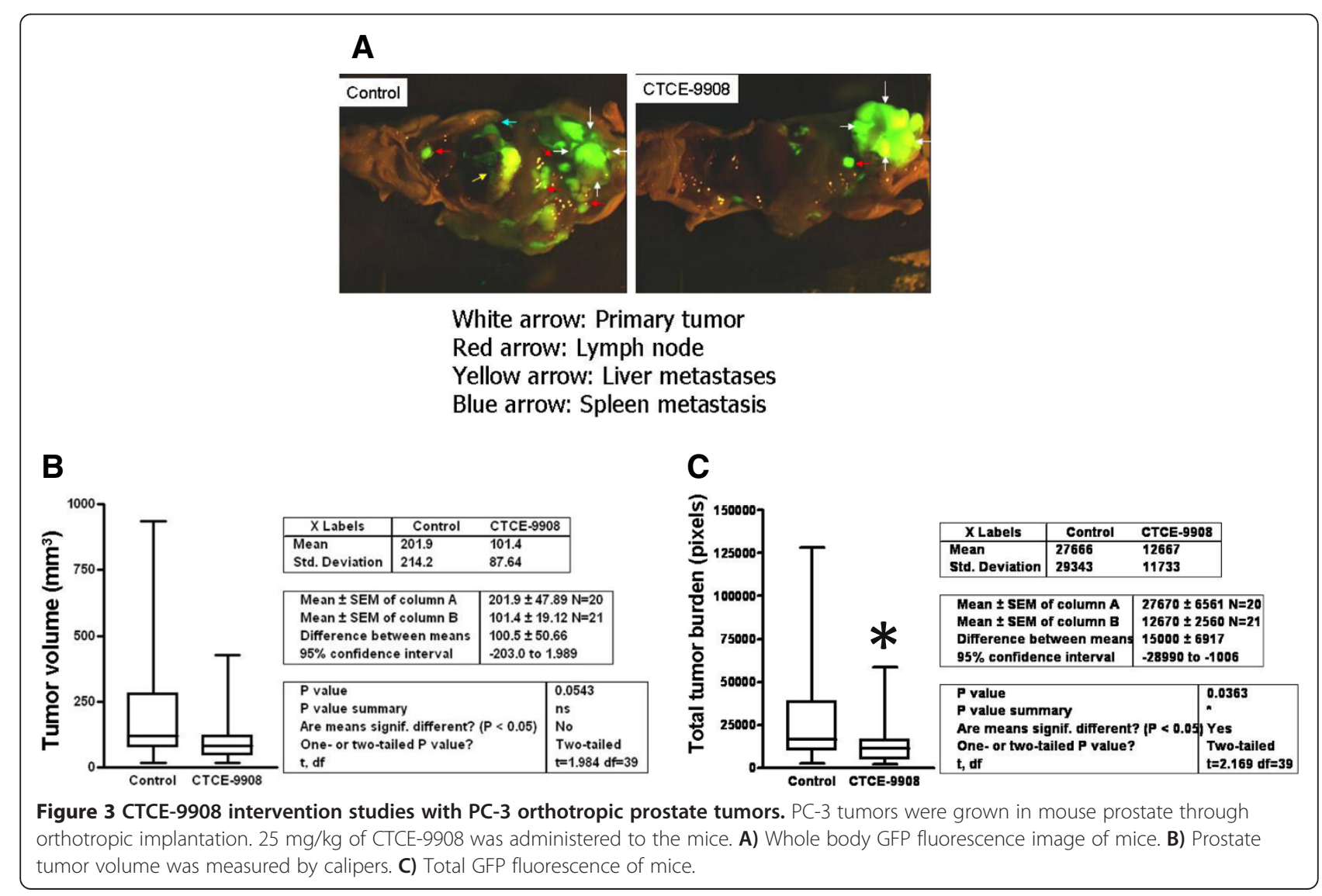


treated tumors have fewer vessels, and these vessels are also smaller in size (Figure 4A). Quantitation of microvessel density in the hot spots of angiogenesis show a reduced CD34-positive vessel density in CTCE-9908 treated tumors (Figure 4B). Moreover, quantitation of CD34 positive vessel density in lymph node metastatic tissue shows a decrease in number in CTCE-9908 treated tumors (Additional file 3: Figure S3). These data suggest that CTCE-9908 treatment inhibited the angiogenesis of primary and lymph node metastatic tumors. The CTCE-9908-mediated inhibition of primary tumor angiogenesis lead to inhibition of metastasis.

\section{Discussion}

Previous studies demonstrate that tumor cells are capable of usurping immune cell chemoinvasive pathways for metastasis to secondary sites. Chemokines and chemokine receptors mediate physiological movement of immune cells in the body. Among the family of chemokine and chemokine receptors mediating tumor cell invasion and metastasis, CXCL12/CXCR4 has gained a central role in different types of tumors in mediating tumor growth, angiogenesis and metastasis. In prostate cancer cells, CXCL12 and CXCR4 play a key role in invasion and metastasis, leading to development and expansion of osseous metastasis. In this study we assessed the effect of inhibition of the CXCL12/CXCR4 pathway by a novel CXCR4 antagonist, CTCE-9908 on in vitro cell proliferation and invasion, and in vivo orthotopic tumor growth, metastasis, and angiogenesis of PC cells.

Previous studies report that CTCE-9908 compound inhibited cell proliferation in PC-3 cells at higher concentrations with no effect at lower concentrations [22]; our data is in line with these studies, as CTCE-9908 compound did not show significant inhibition in cell proliferation at $100 \mu \mathrm{M}$ (which corresponds to $44 \mathrm{nM}$ ) concentration. This lack of inhibitory effect on PC-3 cells can be attributed to the fact that cultured PC-3 cells express low or no CXCL12 [5], and therefore CXCR4 activation could be low in these cells. Previous report by Provasnik et al. support this observation that CTCE-9908 administration do not inhibit the subcutaneous tumor growth [22]. As opposed to cultured cancer cells, in vivo bone tumors express CXCL12 in prostate cancer cells in addition to osteoblasts and endothelial cells. Primary tumors also express CXCL12 in epithelial cells. The CXCL12/CXCR4 axis has been shown to promote cell survival by inhibiting apoptosis in cancer cells; thus, CTCE-9908-mediated inhibition of the CXCL12/ CXCR4 pathway leads to loss of protection from apoptosis and increased cell death. Our data support this notion, as CTCE-9908-treated tumors showed enhanced necrotic areas, suggesting that loss of the CXCL12/CXCR4 axis mediated cell survival leading to enhanced necrosis in tumor cells. But, we cannot rule out the role of growth inhibition of CTCE-9908 in our model as mean tumor growth is inhibited in CTCE-9908 treated group, though the data did not reach statistical significance.
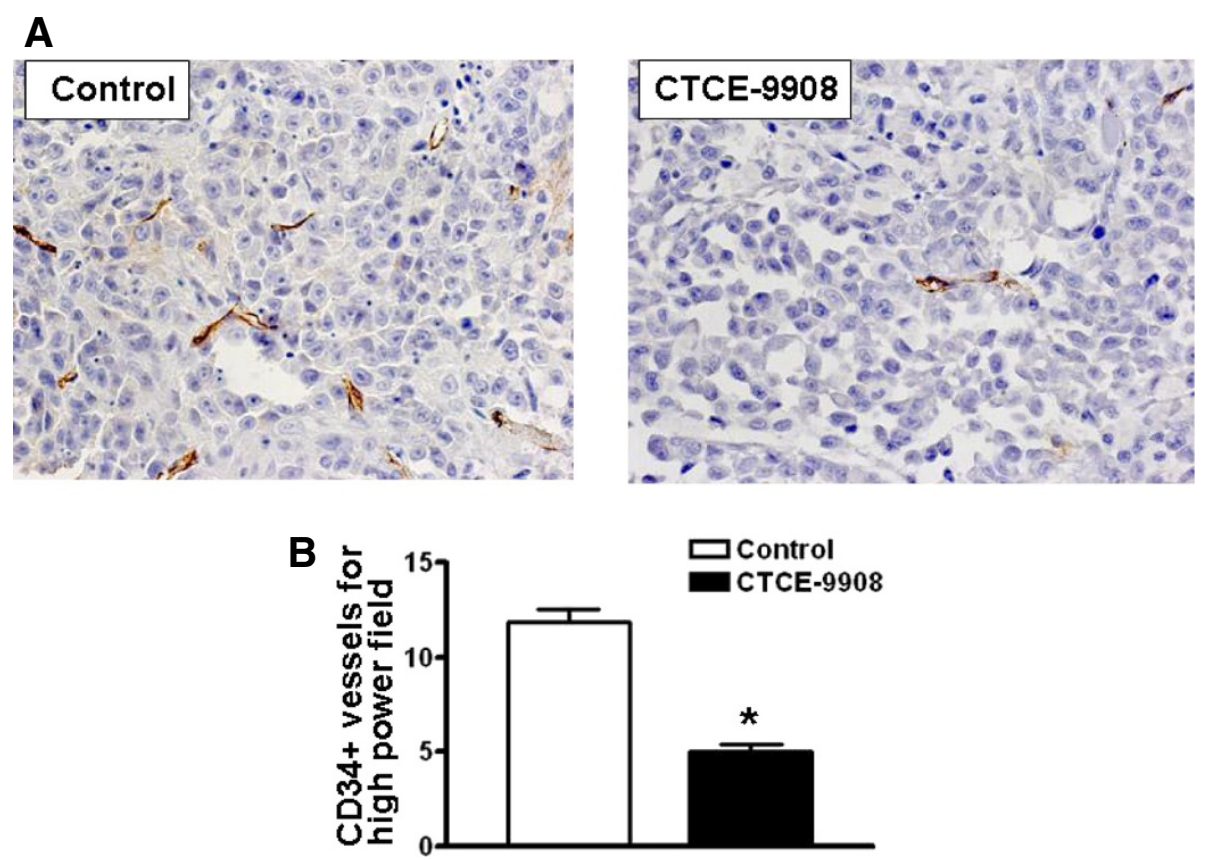

Figure 4 Microvessel density in CTCE-9908-treated PC-3 tumors. A) Prostate tumor tissues were stained with anti-CD 34 antibody. B) Quantitation of CD34+ vessels in control and CTCE-9908 treated prostate tumor tissue. *Represents statistically significant, where $p=0.0021$. 
We have previously shown that the CXCL12/CXCR4 axis in PC-3 cells induce MMP-9 expression via activation of PI3K and MAPK pathways, and this activation mediates in vitro cell invasion of PC-3 cells [24]. Bone colonizing PC-3 cells induce the expression of active MMP-9 at earlier time periods suggesting that CXCL12/CXCR4-mediated homing of PC cells to bone would functionally link with the expression of MMP-9 in local bone tumor microenvironment and induce invasive bone tumor growth [5]. To determine whether CTCE-9908 compound could inhibit invasion of PC-3 cells, we used the lower concentration of $50 \mu \mathrm{g} / \mathrm{ml}$ in cell invasion studies. Although this concentration of CTCE-9908 did not inhibit cell proliferation, our data suggest that $50 \mu \mathrm{g} / \mathrm{ml}$ CTCE-9908 potently inhibited the CXCL12-induced PC-3 cell invasion. To determine whether inhibition of invasion could translate into inhibition of metastasis formation, we treated mice implanted with orthotopic tumors with CTCE-9908. The whole body quantitation of fluorescence measurements shows that CTCE-9908 treatment significantly reduced total tumor burden as a measure of total body fluorescence. To our knowledge, this is the first report to document that targeting the CXCL12/CXCR4 axis through CTCE-9908 inhibited the metastatic burden in an orthotopic prostate cancer model system. Both lymph node and distant metastases were significantly inhibited in CTCE-9908 treated tumors, but distant metastases were strongly inhibited compared to lymph node metastases. Similar observations were found with CTCE-9908 in a breast cancer model where total metastatic burden was significantly inhibited upon CTCE9908 administration [25]. CXCL12/CXCR4 mediated invasive function has implications in clinical management of patients as chemotherapy resistant tumors cells often express high levels of CXCR4 [26] and this may lead to the development of metastases in these patients via CXCL12/ CXCR4 activation. In addtion, prostate cancer progenitor cells express CXCR4 [27] and often these cells are resistant to current chemo and radiation therapy practices, thus, combination therapy with anti-CXCR4 strategies consisting of CTCE-9908 may prevent the further spread of tumor in patients.

Tumor angiogenesis plays a key role in tumor growth and development of metastases. CXCL12/CXCR4 signaling has been shown to modulate the expression of angiogenic cytokines/chemokines in prostate cancer cells [28]. Expression of these proangiogenic factors can recruit endothelial precursor cells to the tumor sites to facilitate angiogenesis. To determine the effect of CXCR4 inhibition on tumor angiogenesis we measured hotspots of angiogenesis in primary and lymph node metastatic tumor tissues for CD34 positive blood vessels. CTCE-9908 treatment significantly inhibited angiogenesis in both primary and lymph node metastases. Porvasnik et al. reported that CTCE-9908 treatment reduced tumor angiogenesis by down regulating
VEGF production and myeloid derived suppressor cell (CD11b positive) recruitment into tumor tissues [22]. CD11b cells have been recently shown to express CXCR4 and migrate towards the CXCL12 expressing cells.

Our studies show that CTCE-9908 is efficacious in inhibiting total tumor burden without significantly reducing primary tumor burden suggesting that targeting CXCL12/ CXCR4 axis may be therapeutically beneficial for the management of prostate cancer patients undergoing chemo or radiation therapy.

\section{Conclusions}

The data presented in the study demonstrate that CTCE-9908 is efficacious in preventing spread of tumor cells from primary site by inhibiting invasive and angiogenic functions of CXCL12/CXCR4 axis in primary tumor environment.

\section{Additional files}

Additional file 1: Figure S1. A) Immunohistochemical analysis of Ki-67 in PC-3 tumors. Control and CTCE-9908 treated prostate tumor tissues were stained for Ki-67 antigen. B) Quantitation of total Ki-67 positive cells in control and treated group. Statistical difference between groups is not significant, where $p=0.0897$.

Additional file 2: Figure S2. Immunohistochemical analysis of cytokeratin in PC3 tumors. Control and CTCE-9908 treated prostate tumor tissues were stained for cytokeratin. Arrow represents low staining necrotic area.

Additional file 3: Figure S3. CD34 staining of lymph node metastasis in control (left) and CTCE-9908 treated mice (right). A representative hot spot of CD34+ vessels is shown. Graphical representation of microvessel densities between control and treated groups of metastatic tumor sections. *represents statistically significant, where $p=0.0296$.

\section{Competing interests}

Dr. Donald Wong and Mr. Walter Korz are the employees of British Canadian Bioscience Corporation.

\section{Authors' contributions}

DW and WK participated in study design and acquisition of animal experimental data. PK carried out immunohistochemical experiments and involved in preparation of figures. SRC is actively involved in all aspects of study and responsible for drafting manuscript. All authors read and approved the final manuscript.

\section{Acknowledgements}

We would like to thank Dr. Charles J. Rosser (MD Anderson Cancer Center Orlando, Orlando, FL, USA) for critically reading and editing the manuscript to improve intellectual content.

Supported by Fund for Cancer Research, U.S. Department of Defense, Idea Award W81XWH-09-1-0250 and NIH R01CA151557 to Sreenivasa R. Chinni.

\section{Author details}

${ }^{1}$ Department of Urology, Wayne State University School of Medicine, 9200 Scott Hall 540 E. Canfield Avenue, Detroit, MI 48201, USA. ²Department of Pathology, Wayne State University School of Medicine, 9200 Scott Hall 540 E. Canfield Avenue, Detroit, MI 48201, USA. ${ }^{3}$ The Barbara Ann Karmanos Cancer Institute, Detroit, MI 48201, USA. ${ }^{4}$ British Canadian BioScience Corporation, Vancouver, Canada.

Received: 6 June 2013 Accepted: 26 December 2013

Published: 28 January 2014 
References

1. Balkwill F: Cancer and the chemokine network. Nat Rev Cancer 2004, 4(7):540-550.

2. Sun $Y X$, Wang J, Shelburne CE, Lopatin DE, Chinnaiyan AM, Rubin MA Pienta KJ, Taichman RS: Expression of CXCR4 and CXCL12 (SDF-1) in human prostate cancers (PCa) in vivo. J Cell Biochem 2003, 89(3):462-473.

3. Wallace TA, Prueitt RL, Yi M, Howe TM, Gillespie JW, Yfantis HG, Stephens RM, Caporaso NE, Loffredo CA, Ambs S: Tumor immunobiological differences in prostate cancer between African-American and EuropeanAmerican men. Cancer Res 2008, 68(3):927-936.

4. Akashi T, Koizumi K, Tsuneyama K, Saiki I, Takano Y, Fuse H: Chemokine receptor CXCR4 expression and prognosis in patients with metastatic prostate cancer. Cancer Sci 2008, 99(3):539-542.

5. Chinni SR, Sivalogan S, Dong Z, Filho JC, Deng X, Bonfil RD, Cher ML: CXCL12/CXCR4 signaling activates Akt-1 and MMP-9 expression in prostate cancer cells: the role of bone microenvironment-associated CXCL12. Prostate 2006, 66(1):32-48.

6. Taichman RS, Cooper C, Keller ET, Pienta KJ, Taichman NS, McCauley LK: Use of the stromal cell-derived factor-1/CXCR4 pathway in prostate cancer metastasis to bone. Cancer Res 2002, 62(6):1832-1837.

7. Arya M, Patel HR, McGurk C, Tatoud R, Klocker H, Masters J, Williamson M: The importance of the CXCL12-CXCR4 chemokine ligand-receptor interaction in prostate cancer metastasis. J Exp Ther Oncol 2004 4(4):291-303.

8. Kukreja P, Abdel-Mageed AB, Mondal D, Liu K, Agrawal KC: Up-regulation of CXCR4 expression in PC-3 cells by stromal-derived factor-1alpha (CXCL12) increases endothelial adhesion and transendothelial migration: role of MEK/ERK signaling pathway-dependent NF-kappaB activation. Cancer Res 2005, 65(21):9891-9898.

9. Singh S, Singh UP, Grizzle WE, Lillard JW Jr: CXCL12-CXCR4 interactions modulate prostate cancer cell migration, metalloproteinase expression and invasion. Lab Invest 2004, 84(12):1666-1676.

10. Chinni SR, Yamamoto H, Dong Z, Sabbota A, Bonfil RD, Cher ML: CXCL12/ CXCR4 Transactivates HER2 in Lipid Rafts of Prostate Cancer Cells and Promotes Growth of Metastatic Deposits in Bone. Molecular cancer research: MCR 2008, 6(3):446-457.

11. Darash-Yahana M, Pikarsky E, Abramovitch R, Zeira E, Pal B, Karplus R, Beider K, Avniel S, Kasem S, Galun E, et al: Role of high expression levels of CXCR4 in tumor growth, vascularization, and metastasis. Faseb J 2004, 18(11):1240-1242.

12. Vaday GG, Hua SB, Peehl DM, Pauling MH, Lin YH, Zhu L, Lawrence DM, Foda HD, Zucker S: CXCR4 and CXCL12 (SDF-1) in prostate cancer: inhibitory effects of human single chain Fv antibodies. Clin Cancer Res 2004, 10(16):5630-5639.

13. Sun $Y X$, Schneider A, Jung $Y$, Wang J, Dai J, Cook K, Osman NI, Koh-Paige AJ, Shim H, Pienta KJ, et al: Skeletal localization and neutralization of the SDF-1(CXCL12)/CXCR4 axis blocks prostate cancer metastasis and growth in osseous sites in vivo. J Bone Miner Res 2005, 20(2):318-329.

14. Dong Z, Bonfil RD, Chinni S, Deng X, Trindade Filho JC, Bernardo M, Vaishampayan U, Che M, Sloane BF, Sheng S, et al: Matrix metalloproteinase activity and osteoclasts in experimental prostate cancer bone metastasis tissue. Am J Pathol 2005, 166(4):1173-1186.

15. Sun X, Cheng G, Hao M, Zheng J, Zhou X, Zhang J, Taichman RS, Pienta KJ, Wang J: CXCL12 / CXCR4 / CXCR7 chemokine axis and cancer progression. Cancer Metastasis Rev 2011, 29(4):709-722.

16. DiPersio JF, Micallef IN, Stiff PJ, Bolwell BJ, Maziarz RT, Jacobsen $E_{i}$ Nademanee A, McCarty J, Bridger G, Calandra G: Phase III prospective randomized double-blind placebo-controlled trial of plerixafor plus granulocyte colony-stimulating factor compared with placebo plus granulocyte colony-stimulating factor for autologous stem-cell mobilization and transplantation for patients with non-Hodgkin's lymphoma. J Clin Oncol 2009, 27(28):4767-4773.

17. Burger JA, Stewart DJ: CXCR4 chemokine receptor antagonists: perspectives in SCLC. Expert Opin Investig Drugs 2009, 18(4):481-490.

18. Kim SY, Lee CH, Midura BV, Yeung C, Mendoza A, Hong SH, Ren L, Wong D, Korz W, Merzouk A et al: Inhibition of the CXCR4/CXCL12 chemokine pathway reduces the development of murine pulmonary metastases. Clin Exp Metastasis 2008, 25(3):201-211.

19. Rubin JB, Kung AL, Klein RS, Chan JA, Sun Y, Schmidt K, Kieran MW, Luster AD, Segal RA: A small-molecule antagonist of CXCR4 inhibits intracranial growth of primary brain tumors. Proc Natl Acad Sci USA 2003, 100(23):13513-13518.
20. Kajiyama H, Shibata K, Terauchi M, Ino K, Nawa A, Kikkawa F: Involvement of SDF-1alpha/CXCR4 axis in the enhanced peritoneal metastasis of epithelial ovarian carcinoma. Int J Cancer 2008, 122(1):91-99.

21. Huang EH, Singh B, Cristofanilli M, Gelovani J, Wei C, Vincent L, Cook KR, LucCi A: A CXCR4 antagonist CTCE-9908 inhibits primary tumor growth and metastasis of breast cancer. J Surg Res 2009, 155(2):231-236.

22. Porvasnik S, Sakamoto N, Kusmartsev S, Eruslanov E, Kim WJ, Cao W, Urbanek C, Wong D, Goodison S, Rosser CJ: Effects of CXCR4 antagonist CTCE-9908 on prostate tumor growth. Prostate 2009, 69(13):1460-1469.

23. Glinskii AB, Smith BA, Jiang P, Li XM, Yang M, Hoffman RM, Glinsky GV: Viable circulating metastatic cells produced in orthotopic but not ectopic prostate cancer models. Cancer Res 2003, 63(14):4239-4243.

24. Bonfil RD, Sabbota A, Nabha S, Bernardo MM, Dong Z, Meng H, Yamamoto $H$, Chinni SR, Lim IT, Chang M, et al: Inhibition of human prostate cancer growth, osteolysis and angiogenesis in a bone metastasis model by a novel mechanism-based selective gelatinase inhibitor. Int J Cancer 2006, 118(11):2721-2726

25. Richert MM, Vaidya KS, Mills CN, Wong D, Korz W, Hurst DR, Welch DR: Inhibition of CXCR4 by CTCE-9908 inhibits breast cancer metastasis to lung and bone. Oncol Rep 2009, 21(3):761-767.

26. Hatano K, Yamaguchi S, Nimura K, Murakami K, Nagahara A, Fujita K, Uemura M, Nakai Y, Tsuchiya M, Nakayama M, et al: Residual prostate cancer cells after docetaxel therapy increase the tumorigenic potential via constitutive signaling of CXCR4, ERK1/2 and c-Myc. Molecular cancer research: MCR 2013, 11(9):1088-1100.

27. Dubrovska A, Elliott J, Salamone RJ, Telegeev GD, Stakhovsky AE, Schepotin IB, Yan F, Wang Y, Bouchez LC, Kularatne SA, et al: CXCR4 expression in prostate cancer progenitor cells. PLoS One 2012, 7(2):e31226.

28. Wang J, Sun Y, Song W, Nor JE, Wang CY, Taichman RS: Diverse signaling pathways through the SDF-1/CXCR4 chemokine axis in prostate cancer cell lines leads to altered patterns of cytokine secretion and angiogenesis. Cell Signal 2005, 17(12):1578-1592.

doi:10.1186/1471-2490-14-12

Cite this article as: Wong et al: Targeting CXCR4 with CTCE-9908 inhibits prostate tumor metastasis. BMC Urology 2014 14:12

\section{Submit your next manuscript to BioMed Central and take full advantage of:}

- Convenient online submission

- Thorough peer review

- No space constraints or color figure charges

- Immediate publication on acceptance

- Inclusion in PubMed, CAS, Scopus and Google Scholar

- Research which is freely available for redistribution 